\title{
Desigualdades territoriales y equidad en el sistema sanitario español
}

\author{
David Cantarero Prieto \\ Departmento de Economía. Universidad de Cantabria
}

\begin{abstract}
Resumen
En este trabajo se analizan las principales diferencias en el sector sanitario por Comunidades Autónomas españolas en dos variables básicas: gasto y financiación. El objetivo de este estudio es relacionar dichas variables en la medida de lo posible con la oferta de servicios sanitarios (acceso y utilización) e indicadores de salud para concluir si las desigualdades que se observen están justificadas por diferencias en la población cubierta, por la necesidad de aprovechar las economías de escala (motivos de eficiencia), etc., o se trata más bien de diferencias poco justificables.

Los resultados muestran que el factor más importante en la explicación de las diferencias entre gasto y financiación es la falta de corresponsabilidad fiscal de los sistemas de financiación sanitaria mientras que otros factores de oferta así como la renta y el grado de descentralización influyen pero pueden ser menos importantes.
\end{abstract}

Palabras clave: economía de la salud, gasto, financiación, oferta, eficiencia, equidad. Clasificación JEL: I1, H7

\begin{abstract}
In this paper the main differences in regional health services in Spain are analyzed in two basic variables: expenditure and financing. The objective of this paper is to link this variables with health care supply (access and utiization) and health indicators, in order to conclude if health inequalities are justified for differences in covered population, advantages of scale economies (efficiency) or it is due to another reasons.

Results show that the most important determinant of differences between health care expenditure and financing is the lack of fiscal co-accountability of autonomous communities health care financing while other supply factors as well as income and degree of decentralization could be less important.
\end{abstract}

Key words: health economics, expenditure, financing, supply, efficiency, equity.

JEL Classification: $I 1, H 7$

\section{Introducción}

En los modernos Estados de Bienestar la sanidad es uno de sus pilares fundamentales y el derecho a la protección de la salud aparece recogido en la Constitución Española (CE) de 1978 habiéndose a su vez consolidado junto con el cambio desde un modelo de Seguridad Social (SS) al actual Sistema Nacional de Salud (SNS, desde la Ley General de Sanidad-LGS de 1986) descentralizado desde 2002 (excepto en 
Ceuta y Melilla). Asimismo, la Ley 16/2003, de 28 de Mayo, de Cohesión y Calidad del SNS, es el marco legal que persigue garantizar la coordinación y cooperación de los distintos Servicios Regionales de Salud (SRS).

Hasta la fecha se han venido produciendo diversas reformas tanto en la financiación autonómica general como en la sanitaria (Ruiz-Huerta y Granado, 2003). En lo que se refiere a este última, se aprobó en 2001 tras una ardua negociación el sistema vígente en la actualidad y que integra a la financiación de las competencias sanitarias de las diez Comunidades Autónomas (CCAA) que en ese año carecían de ellas, habiendo sido ratificado por la Ley 21/2001, de 27 de Diciembre, en las Cortes Generales.

Dicho modelo ha introducido un ajuste por necesidad al criterio per cápita simple sobre la base de otras variables, básicamente la población mayor de 65 años e insularidad además de otros ajustes menores sobre la base de asignaciones de nivelación y fondo «de cohesión» para pacientes desplazados. A pesar de suponer un claro avance, aún queda lejos de lo que sucede en otros países de nuestro entorno donde existen diversos grados de refinamiento de estos modelos de capitación, por ejemplo, introduciendo diferentes categorías individuales según la edad y el sexo (Urbanos, 2001; Banting y Corbett, 2002) aunque condicionadas por la calidad y cantidad de información disponible en cada país.

Los problemas presupuestarios se han venido reproduciendo en los últimos meses como resultado de un cada vez mayor desfase entre el crecimiento de los ingresos y gastos autonómicos, circunstancia ésta última que resulta importante en el caso de la sanidad. A esto, habría que añadir que en el caso de las CCAA las asignaciones de nivelación por aumento de su población para ser efectivas habrían de ser en un año tres puntos por encima del nivel nacional, lo cual al no producirse de modo acumulado difícilmente han llegado a ponerse en práctica.

Precisamente del modelo actual se han efectuado ya tres liquidaciones correspondientes a 2002, 2003 y 2004. El motivo del retraso temporal es la disposición de información sobre impuestos. Los problemas de insuficiencia del gasto sanitario han tenido su reflejo en la aplicación de la garantías de asistencia sanitaria a la mayoría de CCAA en las tres liquidaciones conocidas hasta el momento del modelo de financiación correspondientes a los años 2002 (208,90 millones de euros; $0,73 \%$ del total de la financiación sanitaria, afectando a todas las CCAA excepto Cantabria, Murcia, Canarias y Madrid), 2003 (224,08 millones de euros; 0,73\% del total de la financiación sanitaria, afectando a todas las CCAA excepto a Andalucía, Cantabria, Murcia, C.Valenciana y Madrid) y 2004 (592,83 millones de euros; $1,82 \%$ del total de la financiación sanitaria, afectando a todas las CCAA excepto Murcia, C.Valenciana y Madrid). La aplicación de dichas garantías se ha hecho en virtud del mecanismo transitorio de garantía financiera dinámica por el cual durante los tres primeros años de funcionamiento del nuevo sistema (2002-2004) el Estado garantizará a las CCAA que el índice de evolución de los recursos asignados para sanidad sea el de la evolución del Producto Interior Bruto (PIB) nominal a precios de mercado (Disposición transitoria segunda, de la Ley 21/2001, de 27 de Diciembre). Dicho aspecto es 
importante en sanidad, ya que su índice de evolución de los recursos era hasta el año 2002 el PIB, por lo que puede pensarse que esta garantía financiera es una reminiscencia de los Acuerdos de Financiación sanitaria anteriores de los cuatrienios 19941997 y 1998-2001.

En este sentido, la descentralización sanitaria en nuestro país no parece haber ido acompañada siempre de mecanismos efectivos de coordinación (en recursos humanos, evaluación de tecnologías sanitarias, información sanitaria, sistemas informáticos, políticas de salud pública, etc) que garanticen un nível mínimo de igualdad en todo el SNS (García Gómez y López Nicolas, 2004; Artells, 2005; López I Casasnovas et al., 2005; Gonzalez y Barber, 2006). Como resultado se han producido diferencias entre CCAA en términos de insuficiencia que dificilmente responderán a factores claramente identificados en términos de eficiencia o circunstancias similares. Esto es importante dado que el sistema sanitario español debería ser capaz de combinar en todo su territorio las diferencias entre SRS con la consecución de objetivos de equidad mejorando así el bienestar social. En cualquier caso, es necesario contar con información precisa que posibilite delimitar de manera adecuada las responsabilidades en dichas diferencias entre los niveles central y autonómicos e intentar, en cierto sentido, entenderlas.

Asimismo, tras el Informe del Grupo de Trabajo del Análisis del Gasto Sanitario de la Intervención General de la Administración del Estado (IGAE), en la II Conferencia de Presidentes autonómicos y posterior Consejo de Política Fiscal y Financiera (CPFF) de 2005 se acordaron medidas de carácter temporal, si bien con escasa relación con la corresponsabilidad fiscal, para la mejora de la financiación del gasto sanitario regional.

Por otro lado, el proceso de reforma estatutaria liderado por Cataluña y seguido por otras CCAA pone en cuestión la autonomía y corresponsabilidad del actual sistema de financiación, demandando más capacidad de gobierno para las CCAA tanto en competencias como en financiación. Ambas circunstancias hacen que se esté replanteando el sistema actual de financiación, y prueba de ello ha sido el hecho de que en Diciembre de 2006 el Ministerio de Economía Hacienda haya remitido a las CC.AA un documento que recoge el diagnóstico de la Administración General del Estado (AGE) sobre el funcionamiento del actual sistema de financiación autonómica, dando así cumplimiento al compromiso que el Gobierno adquirió en la reunión del CPFF del pasado 27 de Junio de 2006 y habiendo de las CCAA, sólo Cataluña y Andalucía remitido sus respectivos análisis de situación.

Más volumen de recursos para las CC.AA., más autonomía y una mayor corresponsabilidad son las principales demandas que impulsan esta reforma. Quedan así pendientes, entre otras, estas cuestiones junto con el «cierre» del diseño del Estado de las autonomías en base a la reforma de los diferentes Estatutos que parece seguir un proceso de emulación entre ellos (De la Fuente y Gundín, 2007). La tendencia en la futura reforma del sistema probablemente supondrá incrementos en la capacidad normativa sobre tributos cedidos $y$, por ende, mayores avances en la corresponsabilidad fiscal de las CCAA. 
El objetivo de este trabajo consiste en estudiar en el campo de la sanidad de modo selectivo, y desde la perspectiva económica, la relación existente entre las diferencias autonómicas en el gasto y financiación y diversas variables relacionadas con la oferta de servicios sanitarios (acceso y utilización) e indicadores de salud, tratando así de concluir si las desigualdades que se observen están justificadas, por ejemplo, por diferencias en la población cubierta, por la necesidad de aprovechar las economías de escala (motivos de eficiencia), etc., o se trata más bien de diferencias poco justificables. En todo caso, el grado de aceptabilidad de ciertas desigualdades territoriales es una cuestión no exenta de cierta complejidad y de supuestos normativos cuya contrastación aún no es del todo concluyente a partir de la evidencia empírica.

El trabajo se organiza de la siguiente forma. En el primer apartado se analiza el SNS español así como el proceso de descentralización sanitaria, planteando así algunas de sus ventajas e inconvenientes. En el siguiente apartado se consideran las desigualdades territoriales en cuanto al gasto y financiación planteándose si dichas desigualdades están o no justificadas. Finalmente, se ofrece un apartado final de conclusiones.

\section{Descentralización en el Sistema Nacional de Salud español}

En el contexto, lo suficientemente amplio pero a la vez vago y difuso marcado por la CE de 1978 (Titulo VIII relativo a la Organización Territorial del Estado) en base al sistema de atribución de competencias de «doble lista» del «Estado de las Autonomías», es donde debe enmarcarse e1 marco legal de la sanidad en España. Así, nuestro SNS se define según el art. 44.2 de la LGS de 1986 como «el conjunto de los Servicios de Salud de las CCAA».

Con arreglo a esto, la descentralización sanitaria que ha tenido lugar en España desde la CE puede calificarse como un proceso en el que han predominado los criterios geográficos sobre los funcionales y, según las características de las entidades hacia las que se produce la descentralización, como un proceso de «devolución» (Rey, 1998).

Así, los términos constitucionales del reparto de competencias entre el Estado y las CCAA en lo que se refiere al sistema sanitario supone que el ejercicio real de las competencias se cumple con los denominados Decretos de transferencias, en el que se determinan de manera pormenorizada los medios materiales y personales que cada CCAA recibe para el desarrollo de esas funciones. Hasta justo antes de que en 2002 se hubiese generalizado el proceso transferencial en sanidad, las competencias habían sido transferidas a siete CCAA según Reales Decretos de Traspasos de las funciones y servicios del INSALUD (Cataluña en 1981, Andalucía en 1984, País Vasco en 1988, C. Valenciana en 1988, Galicia en 1991, Navarra en 1991 y Canarias en 1994). Este grupo de CC.AA gestionaba la sanidad a través de sus respectivos SRS, resultado de nuestro sistema autonómico unidireccional que no contempla la posibilidad de otra evolución que no sea la descentralizadora, mientras que el Instituto Nacional 
de Salud (INSALUD) mantenía hasta 2002 la gestión sanitaria en las diez regiones restantes (INSALUD-Gestión Directa).

Es a partir de esa fecha cuando la estructura del sistema sanitario ha sufrido un cambio cualitativo trascendental hasta el punto de que el SNS ha pasado a descomponerse en diecisiete SRS, que vienen a suponer alrededor de un 35\% del presupuesto de gastos de cada CCAA, con toda la heterogeneidad derivada de las propias políticas sanitarias y su gestión (López I Casasnovas, 2004). La armonización de estos SRS precisa de unas dosis de coordinación difícilmente imaginables en la situación anterior centralizada, lo que puede redundar en su caso en ciertos problemas de eficiencia y equidad.

En cuanto a gasto coexisten un sector sanitario público mayoritario y uno privado de carácter secundario cada vez mayor, indicativo de su importancia como complemento del público o de la sensibilidad del incremento de renta y la mayor demanda social de sanidad. En ese sentido, la necesidad estructural de un volumen de recursos cada vez mayor, origen de ese gasto creciente, ha alterado las fuentes tradicionales de financiación de la sanidad pública española para intentar garantizar su suficiencia financiera estableciéndose la universalización de la asistencia sanitaria sobre la base la equidad y solidaridad.

Ese proceso descentralizador ya finalizado ha supuesto primero valorar y determinar el cuánto del volumen de gasto asociado al conjunto de competencias que la CE atribuye o el Estado por Ley Orgánica transfiere a las CCAA y, en un segundo momento, ha respondido al cómo se financian las Haciendas autonómicas en el nuevo marco de un sector público descentralizado (Acuerdos de financiación autonómica sanitaria hasta el año 2001 y modelo actual de financiación autonómica general desde el año 2002 de carácter integrador e indefinido así como acuerdo de mejora de la financiación sanitaria de 2005).

\section{Desigualdades territoriales en el Sistema Nacional de Salud español}

En este apartado se se analizan las principales diferencias en el sector sanitario por CCAA españolas en dos variables básicas: gasto y financiación. A continuación, se relacionan dichas variables en la medida de lo posible con la oferta de servicios sanitarios e indicadores de salud, tratando así de concluir si las desigualdades que se observen están justificadas.

\subsection{Desigualdades territoriales en el gasto}

El Informe de Gasto Sanitario planteado por la IGAE junto con la participación de las CCAA (Tabla 1), estima que el importe del total de gasto consolidado (todas las Administraciones Públicas-AAPP) real ha sido de unos 42.626 millones de euros, es decir, un $14,45 \%$ del gasto de las AAPP y constituye la segunda política de gas- 
to cuantitativamente más importante después de la política de protección social (García Goñi, 2006; Urbanos, 2006b). La deuda extrapresupuestaria ha supuesto unos 1680 millones de euros para dicho ejercicio, muy por encima de los aproximadamente 68 millones de euros de 1999 y de los valores de 2000, 2001 y 2002 (463, 439 y 597 millones de euros respectivamente).

\section{TABLA 1}

EVOLUCIÓN DEL GASTO SANITARIO PÚBLICO (MILLONES DE EUROS CORRIENTES). ESPAÑA

\begin{tabular}{|l|c|c|c|c|c|}
\hline \multicolumn{1}{|c|}{ Año } & $\mathbf{1 9 9 9}$ & $\mathbf{2 0 0 0}$ & $\mathbf{2 0 0 1}$ & $\mathbf{2 0 0 2}$ & $\mathbf{2 0 0 3}$ \\
\hline $\begin{array}{l}\text { Gasto total consolidado AAPP } \\
\text { \% sobre el PIB } \\
\text { \% sobre gasto de las AAPP }\end{array}$ & $\begin{array}{c}30.635,60 \\
5,42 \\
13,48\end{array}$ & $\begin{array}{c}33.092,18 \\
5,42 \\
13,57\end{array}$ & $\begin{array}{c}35.499,47 \\
5,43\end{array}$ & $\begin{array}{c}38.295,36 \\
5,48\end{array}$ & $\begin{array}{c}42.626,47 \\
13,72\end{array}$ \\
$\begin{array}{r}5,72 \\
14,45\end{array}$ \\
\hline \% Var. Interanual AAPP & & 8,02 & 7,27 & 7,88 & 11,31 \\
\hline \% Var. Interanual Sector CCAA & & 8,63 & 7,08 & 8,56 & 11,53 \\
\hline
\end{tabular}

FUENTE: Informe del Grupo de Trabajo sobre Gasto Sanitario (2005).

En cuanto al PIB, el gasto sanitario público (liquidado) llevado a cabo por todas las Administraciones Públicas españolas en 2003 ha pasado a ser del 5,72\% frente al $5,42 \%$ de 1999 y 2000 y el 5,43\% de 2001. Puede observarse como en 2002 pasa a ser del 5,48\%, creciendo en casi tres décimas respecto a los valores de años anteriores dado que es cuando en ese momento todas las CCAA pasaron a disponer de la gestión de competencias sanitarias. Además, el crecimiento interanual de la partida correspondiente a las CCAA ha sido de 11,53\% en 1999-2003 repuntando así por encima del crecimiento del PIB nominal. A pesar de su importancia en relación con otras políticas públicas, la clásica comparación con los Estados miembros de la UE-15 de las cifras de gasto sanitario público sobre el PIB indica que el gasto destinado a la sanidad pública es relativamente bajo con respecto a la media europea situada entorno al 6,3\% en 2002 (OECD Health Data, 2006b)

El crecimiento del gasto en sanidad y sus diferencias entre territorios una vez se avanza en los procesos de descentralización no es algo únicamente característico de nuestro país sí se examina la experiencia comparada (Giannoni y Hitiris, 2002; Cantarero, 2003). Así, en el caso concreto de nuestro país habría que añadir también los posibles efectos derivados de la asunción de competencias sanitarias por todas las CCAA del artículo 143 de la CE en el año 2002 (Tabla 2).

En cuanto a la distribución autonómica del gasto en España, el gasto promedio (liquidado) por persona protegida en 2003 ha sido de 988 euros y en 2005 el inicial ha sido de 1094 euros existiendo diferencias entre las CCAA, bien debido a que el re- 
parto no sigue estrictamente el criterio capitativo bien porque en los últimos años las CCAA cuentan con más recursos propios y realizan esfuerzos fiscales distintos. El valor mínimo se ha alcanzado en 2003 en Madrid con 870 euros y en 2005 en C.Valenciana con 924 euros. El máximo fue en 2003 de 1.089 euros en Navarra y en 2005 de 1.240 euros en La Rioja. El coeficiente de variación ha sido en ese año 2003 del 6,23\% y en 2005 del 7,88\%, lo que indica que desde el año 2000 la dispersión del gasto sanitario por persona protegida ha crecido aunque aún lejos de los valores de 1992-1994 motivados por problemas de deuda sanitaria. En cualquier caso, el crecimiento entre 1999-2003 del gasto sanitario per cápita ha mantenido un crecimiento medio del $7,27 \%$ y en $2005-2003$ ha sido del $17,89 \%$.

Las diferencias en gasto per cápita en sanidad no son estrictamente un refejo de inequidad en el sistema dado que España viene siendo un país con cierta homogeneidad interna en el gasto a la vista de la experiencia comparada. Otra forma de explicar el origen del crecimiento del gasto sanitario público y sus diferencias territoriales consistiría en descomponer dicho crecimiento en los factores que según la literatura lo determinan: demografía (gasto por persona protegida y su envejecimiento), el incremento de la cobertura poblacional, los precios implícitos en el gasto sanitario público y la prestación real media por persona.

La metodología de descomposición del gasto aplicada a los datos españoles para 1999-2003 ofrece los siguientes resultados: a pesar del fuerte incremento poblacional en ese mismo período, el componente demográfico (envejecimiento, aumento de la esperanza de vida, etc) «sólo» explica un $21,35 \%$ de la tasa anual media de crecimiento del gasto sanitario público, la prestación real media (mayores remuneraciones, incorporación de nuevas prestaciones y tecnologías cada vez más sofisticadas, etc) explica un 32,65\% y la evolución de los precios (farmacia y otras tecnologías, básicamente) el 46,1\% restante (Informe del Grupo de Análisis del Gasto Sanitario, 2005). Hay que destacar que, según cuál sea el período de análisis, el factor precios y la prestación real media se disputan el primer puesto entre los principales impulsores del gasto. La demografía, en cambio, resulta sistemáticamente, en estudios de carácter nacional y también internacional (OECD, 2006a), el factor menos importante. Lo que no implica que el proceso de envejecimiento progresivo en buena parte de los países desarrollados, y en particular España, ejerza una influencia menor sobre el gasto, si tenemos en cuenta que los cambios en la estructura de la población también repercuten sobre la intensidad de uso de los servicios sanitarios - especialmente con el paso del tiempo-, y este efecto no queda recogido en el factor demográfico.

En este contexto, aunque, de acuerdo con la evidencia empírica disponible, son los precios y la prestación real media por persona los que tienen mayor peso como factores explicativos del crecimiento, el factor demográfico ha cobrado especial relevancia en España debido a la evolución que ha registrado la población protegida desde el 2000. Lógicamente, los incrementos de la cobertura poblacional son ya escasos al ser de facto nuestro sistema sanitario un SNS. Los factores explicativos de dichas divergencias en nivel y evolución del gasto sanitario territorial obedecen a lo siguiente: 


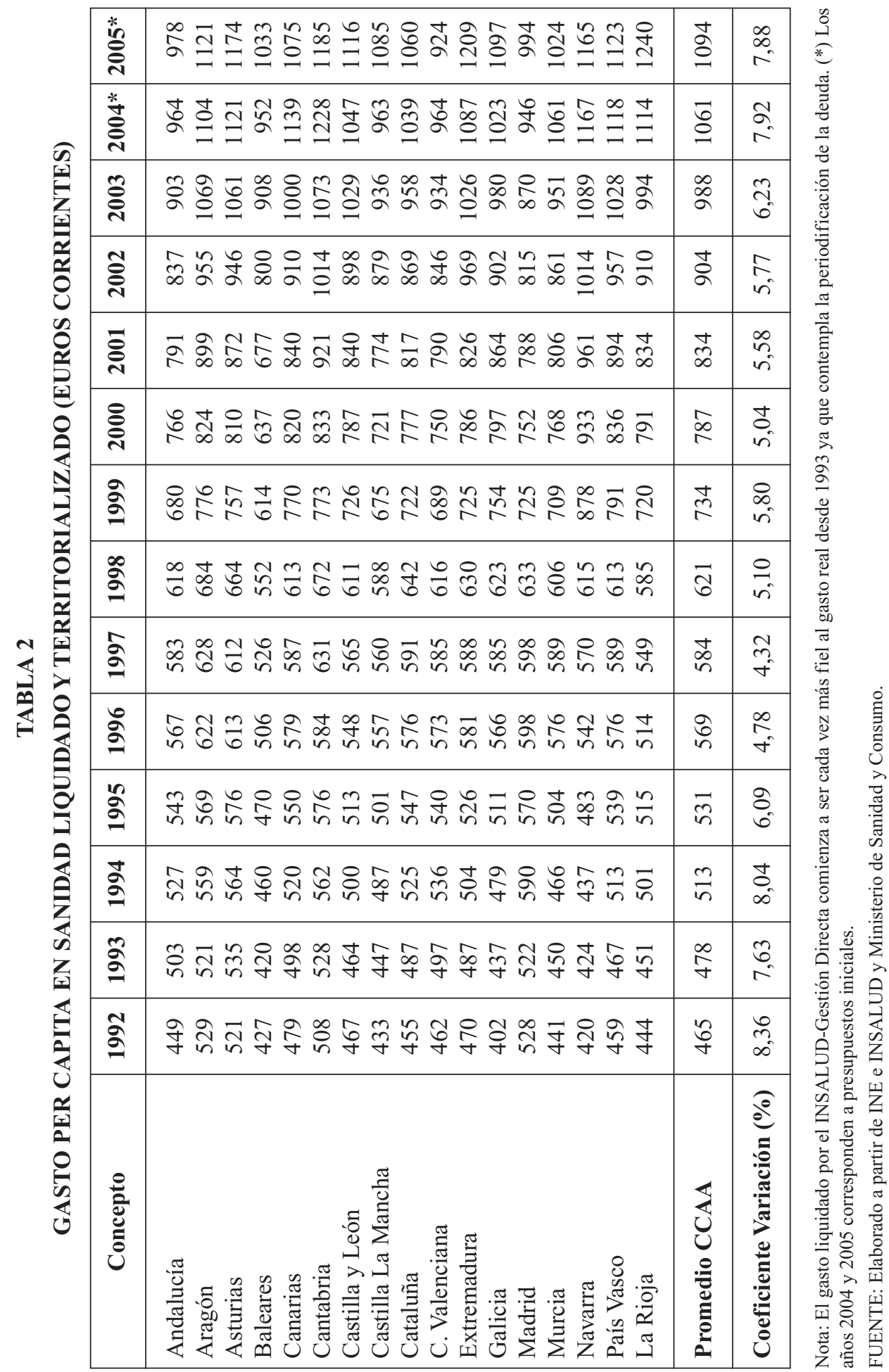


1. El factor demográfico: Puede dividirse, a su vez, en dos elementos: el derivado de los aumentos en el nivel de población, y el que se refiere al cambio en la estructura de edades.

Según las cifras mostradas en la Tabla 3, la población protegida ha crecido en 2005-1999 como media al 10,39\% siendo ese incremento importante en CCAA como Baleares, Murcia, Canarias, Madrid y C.Valenciana además de que en 2005 el aumento global (2,31\%) fue superior al resto de años. El crecimiento de la población protegida de alguna CCAA ha llegado a rondar el límite del 3\% por encima del crecimiento medio nacional, lo que a propuesta de la CCAA de referencia hubiese permitido activar las asignaciones de nivelación para los servicios públicos básicos (sanidad y educación), tal y como se establecía en la CE y en la propia reforma de la Ley Orgánica de Financiación de las CCAA (LOFCA) en 2001. Al tomarse como referencia el incremento poblacional en términos relativos, y no absolutos, y dada la distribución de población actual en el conjunto del Estado, ninguna CCAA ha cumplido este requisito. Las asignaciones de nivelación parecen así estar diseñadas para dar respuesta a shocks demográficos puntuales y extraordinarios en el tiempo y espacio. Esto plantea la necesidad de actualizar las variables de reparto del actual modelo de financiación autonómica (en especial, la población protegida) que habían sido consideradas en el año base 1999 pero que, al no aplicarse hasta 2001, no estaban recogiendo el desfase producido en ese período.

Al margen de los efectos derivados de los aumentos de la población protegida, es preciso tener en cuenta que su progresivo envejecimiento también presiona al alza sobre el gasto, dado que no todos los sujetos efectúan un gasto sanitario «equivalente». Las necesidades de gasto sanitario a nivel regional deberían corregirse en función de su estructura poblacional, incluso no sólo considerando el hecho de que la población mayor consume más servicios sanitarios que el ciudadano medio sino también que esto sucede para la población infantil. Así, en el seno del Grupo de Trabajo sobre Gasto Sanitario se proponía la estimación de necesidades de gasto en términos de «usuarios equivalentes» y mientras un sujeto de edad entre 45 y 54 años gasta en términos hospitalarios un 0,840 de la media, una persona mayor de 75 años hace un consumo de 3,116 veces la media de gasto hospitalario per cápita. Idem para una persona menor de 4 años al hacer un consumo de 1,190 veces la media de gasto hospitalario per cápita. Estas diferencias son incluso mayores para el caso del gasto farmacéutico donde los sujetos de edades entre 65 y 74 años y los mayores de 75 años consumen 3,21 y 4,30 veces la media del gasto farmacéutico per cápita.

El fenómeno del envejecimiento de la población no es algo coyuntural. Sin embargo, y ante la inexistencia para la gran mayoría de la población de un sistema de atención a la dependencia hasta su puesta en marcha en 2007, es frecuente que se desplace al sistema sanitario - y en particular al hospitalario - la atención a problemas que no necesitan estrictamente una prestación sanitaria, sino social o, en todo caso, sociosanitaria. Si se observan las proyecciones elaboradas por el INE, cabe destacar que la población de 65 o más años prácticamente duplicará su peso relativo sobre el total de población, al pasar del 16,80\% en el año 2005 al 30,85\% en el año 2050. Obviamen- 
te, el aumento de gasto sanitario que se produzca como consecuencia de las alteraciones demográficas puede considerarse como exógeno, al no estar influido por las decisiones de política sanitaria de las CCAA.

2. Los precios sanitarios y la prestación real media por persona: Estos elementos se verán impulsados por distintas partidas, entre las que destacan los siguientes:

a) Gastos de personal. Por lo que respecta a los sueldos y salarios, se registran notables diferencias entre CCAA, de forma que las CCAA que habían asumido los traspasos antes de 2002 presentan, en general, un mayor nivel de remuneraciones (Gordo, 2002). La generalización de los traspasos ha hecho que se produzcan aumentos importantes de los gastos de personal en un intento de equiparación entre CCAA.

b) Gasto en medicamentos y productos sanitarios. En este caso, la presión de los precios de los nuevos medicamentos y material terapéutico será la que haga crecer el gasto. El consumo hospitalario está adquiriendo una especial importancia además variar en todas las CCAA debido a las diferencias en la gestión de compras de este tipo de productos, recomendándose desde el Grupo de Trabajo, centralizar las compras en cada ámbito territorial.

c) Consumo intermedio (gasto en bienes y servicios para producir servicios sanitarios públicos). El impacto de las nuevas tecnologías supone incrementos de costes por subidas en los precios y por permitir la extensión de la cantidad y calidad de las prestaciones a colectivos más amplios. El final del proceso de descentralización sanitaria en 2001 pudiera tener efectos derivados de la pérdida de capacidad de negociación con los proveedores de algunos SRS de las CCAA más «pequeñas» (en términos de volumen de población y de gasto), lo que supone un coste de producción más elevado.

d) Gasto en inversiones y capital. Mantener el número de centros de atención primaria y hospitales, así como incorporar nuevos equipamientos médicos, transporte sanitario, tecnologías de la información, etc., requerirá mayores aumentos en el gasto total y diferencias entre CCAA.

En definitiva, los factores que determinan el gasto sanitario son múltiples y variados, y su efecto sobre el gasto actual y futuro de cada CCAA así como en sus diferencias difícil de cuantificar. Además, en lo referido a las causas de crecimiento del gasto, la competencia entre CCAA puede tender a impulsarlo al alza tal y como predice la Teoría del Federalismo Fiscal al exportarse medidas y procesos de innovación de otras CCAA que pueden suponer finalmente un mayor coste. Si no se frena la espiral de oferta de nuevas prestaciones, el aumento generalizado de las remuneraciones, etc, en el medio plazo volverán a detectarse insuficiencias financieras importantes. En todo caso, también debe reforzarse en este ámbito el papel cooperativo a desarrollar por las CCAA en el seno del Consejo Interterritorial del SNS. 


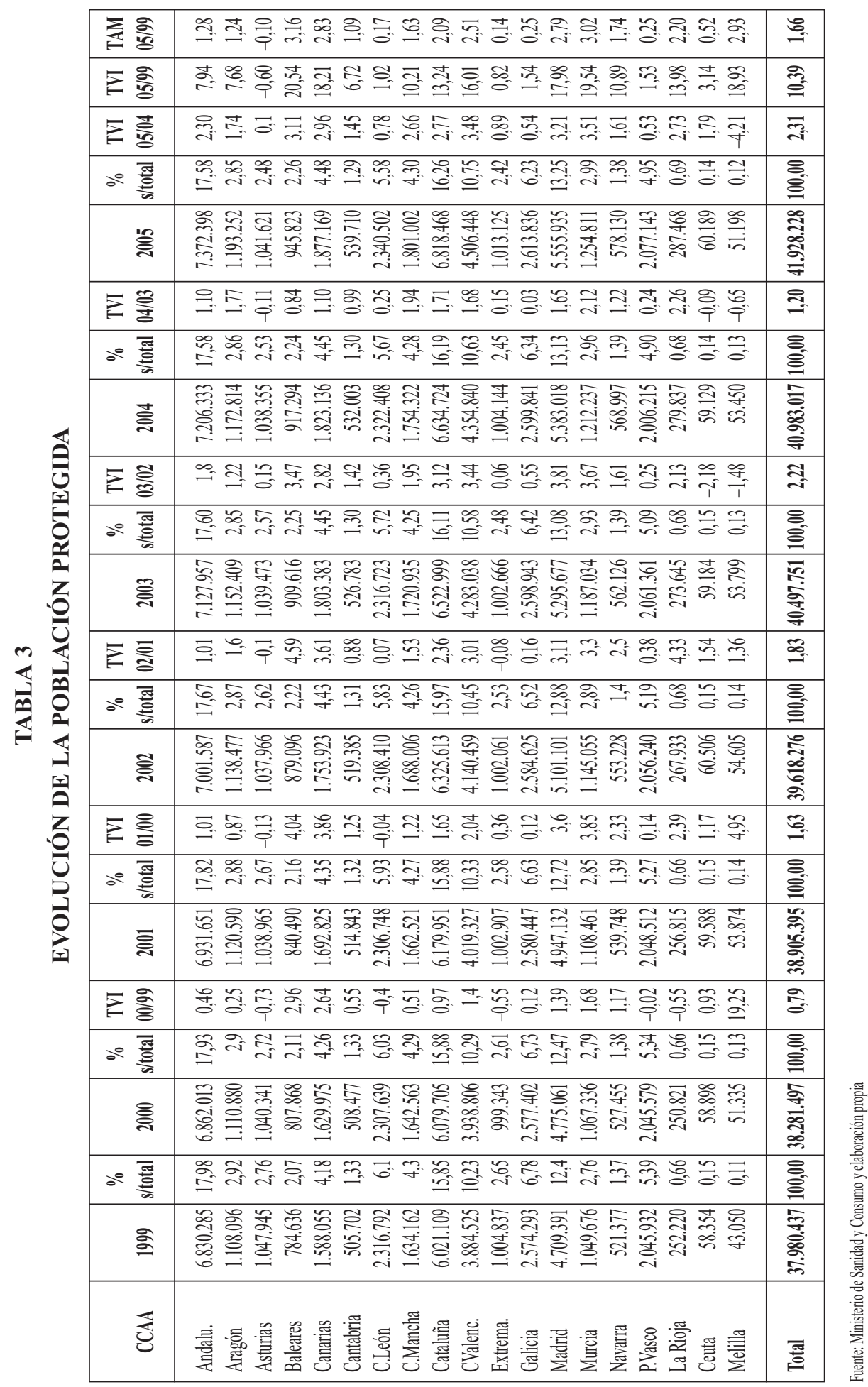


Por último, indicar que las diferencias de gasto sanitario público per cápita podrían deberse a ineficiencias en el sistema aunque no siempre gastar más en sanidad suponga gastar mejor. En este sentido, en Cantarero (2005) se muestra como el gasto sanitario regional depende en parte del envejecimiento de la población, de la renta así como de caracteristicas estructurales de oferta. En Costa-Font y Pons-Novell (2006) se plantea econométricamente que para 1992-1998 con la descentralización el gasto sanitario público se ha incrementado, gastando más per cápita las CCAA forales que las de régimen común así como depende de la disponibilidad de inputs. También plantean la existencia de interacciones espaciales por las cuales el gasto sanitario público se ve influido por el gasto de las CCAA limítrofes (Urbanos, 2006a).

A la vista de lo anteriormente señalado y aunque en el estudio sobre el gasto sanitario de 2005 no quedaba claro cual es el principal motivo que impulsa su crecimiento (demografía, exceso de demanda, ineficiencias en la gestión, o un compendio de todos) si se constata que evoluciona por encima del PIB, y que muchas CCAA se encuentran con dificultades al financiar su oferta sanitaria. De hecho a continuación comprobaremos las soluciones para la financiación y sus diferencias entre CCAA.

\section{Desigualdades territoriales en la financiación}

En el modelo de financiación precisamente es la relativa a la sanidad la receptora de unos recursos mínimos que se vinculan anualmente a la evolución de los ingresos tributarios del Estado (ITE) según números 1 y 2 de la Disposición Transitoria Segunda de la Ley 21/2001, de 27 de Diciembre. En el caso del ejercicio 2004 (Tabla 4), la financiación sanitaria ha ascendido a unos 32.570,94 millones de euros con índices de crecimiento por encima del índice de evolución del PIB nominal a precios de mercado 1999-2004 (1,4143) en sólo tres CCAA: Murcia (1,4283), Comunidad Valenciana $(1,4142)$ y Madrid $(1,4464)$.

Por otro lado, las garantías de financiación sanitaria pueden entenderse en este caso de dos modos. Por un lado, para que aquellas CCAA del antiguo INSALUDGestión Transferida no perdiesen con el cambio del sistema no siendo de aplicación en este caso dada la positiva evolución de la financiación sanitaria. Así, las CCAA que tenían la sanidad traspasada antes de 2001, han recibido asimismo en el año 2002 la liquidación del sistema 1997/2001, como transferencia finalista. Por otro, las garantías pueden entenderse como un mecanismo transitorio de garantía financiera dinámica por el cual durante los tres primeros años de funcionamiento del nuevo sistema (2002-2004) el Estado garantizará a las CCAA que el índice de evolución de los recursos asignados para sanidad sea el de la evolución del PIB nominal a precios de mercado (Disposición transitoria segunda de la Ley 21/2001, de 27 de Diciembre). No obstante, esta garantía ha sido ampliada tras el acuerdo de mejora de la financiación sanitaria de Septiembre de 2005, y hasta tanto se apruebe un nuevo sistema de financiación autonómica como consecuencia de la II Conferencia de Presidentes Autonómicos. 
Estas mejoras de los recursos que pasaron a recibir las CCAA para financiar su sanidad en Septiembre 2005-Diciembre 2006 suponían unos 4359,8 millones de euros adicionales a los ya proporcionados por el sistema actual. La distribución de estos recursos en términos generales era de 1.677 millones de euros con cargo a los Presupuestos Generales del Estado (PGE) en 2006, 1.365,8 millones de euros de anticipos en 2005 y otros 1.365,8 millones de euros en 2006. Además, este aumento de recursos que hace el Estado, podía incrementarse si las CCAA hacían uso de su capacidad normativa. Es difícil determinar si este Acuerdo ha supuesto el cierre definitivo de la polémica sobre la financiación, al seguir existiendo elementos de inyección de financiación ad-hoc con agravios comparativos entre regiones e incremento de las diferencias territoriales.

Las necesidades totales estimadas para el año base en financiación sanitaria, que se cifraban en 23.374,31 millones de euros, han crecido entre 1999 y 2004 a un índice acumulado de 1,3935 hasta alcanzar los 32.570 millones de euros. El procedimiento de cálculo para aislar la financiación sanitaria que corresponde a cada región ha consistido en aplicar a la financiación definitiva total en 2004 el porcentaje que la restricción inicial sanitaria del año 1999 representaba sobre la restricción inicial total en cada territorio, por lo que las garantías aplicadas en el primer año del funcionamiento del sistema suponen un porcentaje relativamente más alto de la financiación sanitaria en Baleares, Galicia, Castilla y León y Asturias.

El crecimiento del ITE nacional acumulado $(1,3325)$ en 2004 vuelve a ser por tercer año consecutivo inferior al PIB (1,4143), si bien únicamente se utiliza el PIB nominal como garantía de crecimiento de la financiación sanitaria. En su conjunto el crecimiento del ITE en 2004 apenas si llega al 3,7\% debido principalmente a la reforma del IRPF. Este bajo crecimiento de una buena parte de la financiación de las CC.AA. provoca que en 2004 sean 13 las CCAA que reciben garantías al crecimiento de la financiación sanitaria. Así el volumen total de recursos asciende a 592,83 millones de euros y sólo Murcia y Madrid no reciben nada por este concepto. Precisamente, las CCAA en las que se ha aplicado una mayor garantía en valores absolutos son Galicia (107,11 millones de euros) y Castilla y León (99,33 millones de euros) con bajos índices de crecimiento en el período 1999-2004 (1,3526 en ambas), debiendo éstas priorizar el gasto sanitario frente a otras competencias asumidas en el futuro.

Aunque el total de financiación real crece por encima del PIB, al determinar la correspondencia o no de garantías sanitarias se utiliza la recaudación estándar o normativa de Tributos Cedidos para así no desincentivar los esfuerzos recaudatorios de las CC.AA. Así, de acuerdo con los índices de evolución de la financiación con criterio normativo son 13 las CCAA cuyos recursos crecen por debajo del PIB y que, tal y como se aprecia en la Tabla 4, son destinatarias de una transferencia complementaria. De todas ellas es destacable la situación de Baleares cuyos recursos crecen al mismo ritmo del ITE nacional a pesar de su alto grado de autonomía. El considerable peso del IVA y de los Impuestos Especiales en el conjunto de sus recursos, y el pobre crecimiento de estos últimos pueden ser el motivo de esa evolución. También 
influye el alto peso de los Tributos Cedidos normativos cuya evolución es según el ITE y no con su recaudación real. Comparando con el año 2003 destaca el incremento de CCAA que necesitan garantías en su financiación sanitaria. Así, Andalucía, la C.Valenciana vuelven en 2004 a recibir garantías sanitarias mientras que en 2003 no las necesitaron (aunque si en 2002). Cantabria por primer año entra en el reparto de garantías sanitarias.

La Tabla 5 recoge la financiación per cápita para la prestación sanitaria, en 1999 y 2004 tomando como denominador la población protegida y no la población total por considerar que se ajusta mejor a los usuarios del servicio (Cantarero y Fernández Gómez, 2007). En 1999 la variación en la financiación per capita de este servicio era de un $8 \%$ siendo La Rioja (al igual que en la financiación total) la Comunidad que más recursos per cápita recibe para financiar la sanidad, en concreto 804,31 euros por usuario. Por el contrario, la que menos financiación recibe es Madrid con 622,43 euros por usuario. Como ocurre con la financiación total el punto de partida es desigual reflejando un determinado patrón de distribución de los recursos y aunque el peso de la población protegida es de un $75 \%$, el resto corresponde a la población mayor de 65 años. El tomar en el denominador un índice ponderado de estas dos variables no cambia el resultado en términos de dispersión siendo los coeficientes variación los mismos y la posición relativa de la CCAA apenas varía.

Cuando el modelo evoluciona hasta 2004, se produce una mayor variación en la financiación per cápita. El coeficiente de variación se incrementa hasta el 11\% en 2004 con independencia de que tómenos los recursos antes o después de haberse recibido las garantías. Murcia es la CCAA que menos recursos recibe en el año 2004, 795,55 euros por usuario, sin haber recibido en ese año la garantía de crecimiento, y Cantabria con 1.063,30 euros por usuario se convierte en la CCAA que dispone de más recursos para destinar a la sanidad, siendo el primer año que necesita la garantía de crecimiento.

En cuanto al crecimiento de los recursos la financiación per cápita crece menos que los recursos absolutos debido a que, en conjunto, los usuarios crecen un 7,6\% desde 1999. La CCAA con mayor crecimiento de los recursos para sanidad es Asturias $(1,4285)$ y si tomamos los valores absolutos la de mayor crecimiento es Madrid. La que menos crece en términos per cápita es Baleares debido a que su población protegida crece un $16 \%$ entre 1999 y 2004, aunque en términos absolutos también es la Comunidad que experimenta un menor crecimiento.

Como resultado, en la práctica, las fórmulas de financiación autonómica no responden en España a objetivos claros de disminución de las desigualdades territoriales ya que, por ejemplo, el denominado «fondo de cohesión» (RD 1247/2002), apenas cubre en la práctica la atención de los flujos de pacientes desplazados, ni de pacientes extranjeros. Hace que las CCAA pretendan emitir pacientes a otras CCAA sin asumir costes, dado que no se explican claramente las condiciones y requisitos para el desplazamiento de pacientes (es decir, no funciona como una cámara de compensación entre CCAA). 
DESIGUALDADES TERRITORIALES Y EQUIDAD EN EL SISTEMA SANITARIO ESPAÑOL 155

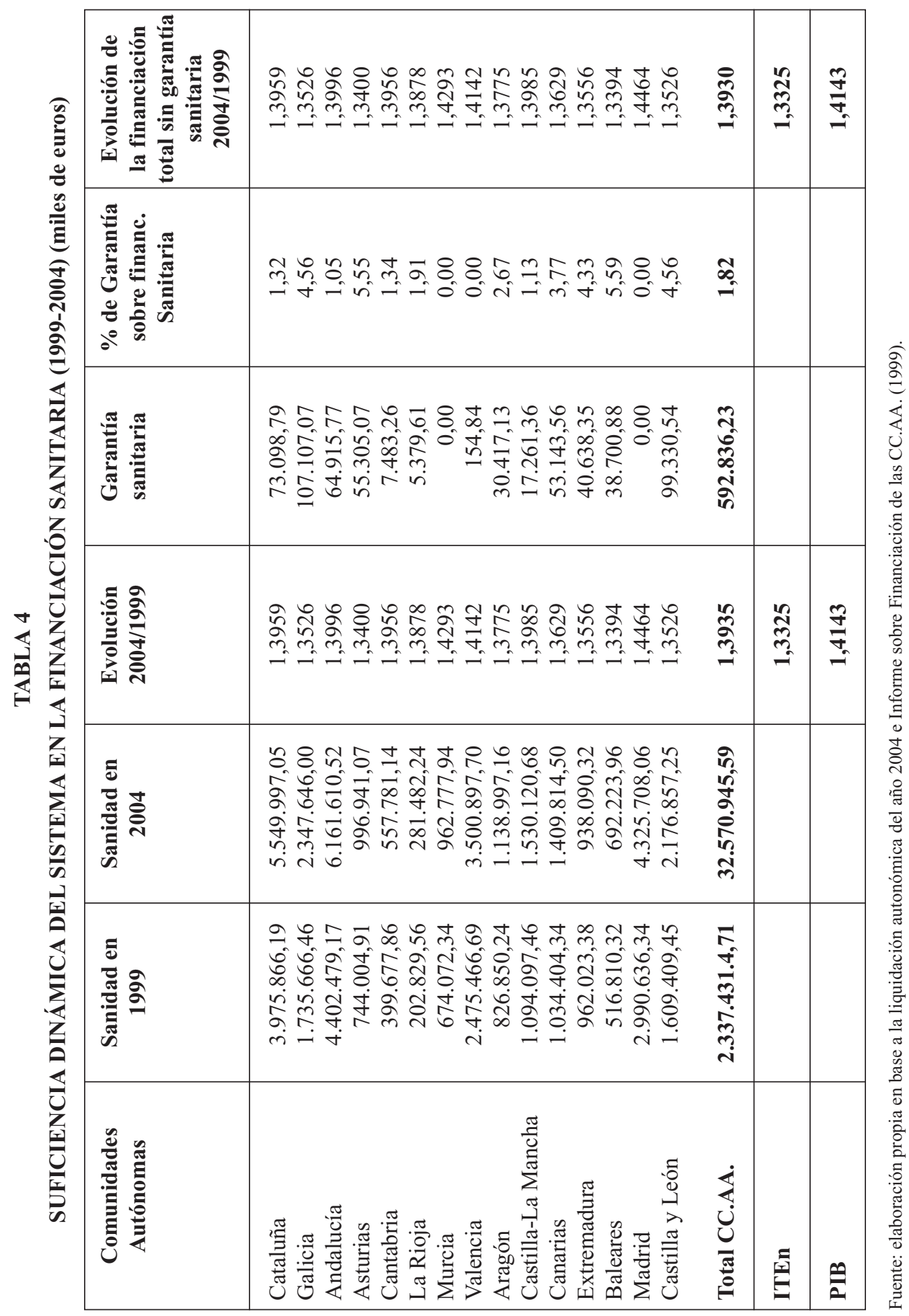




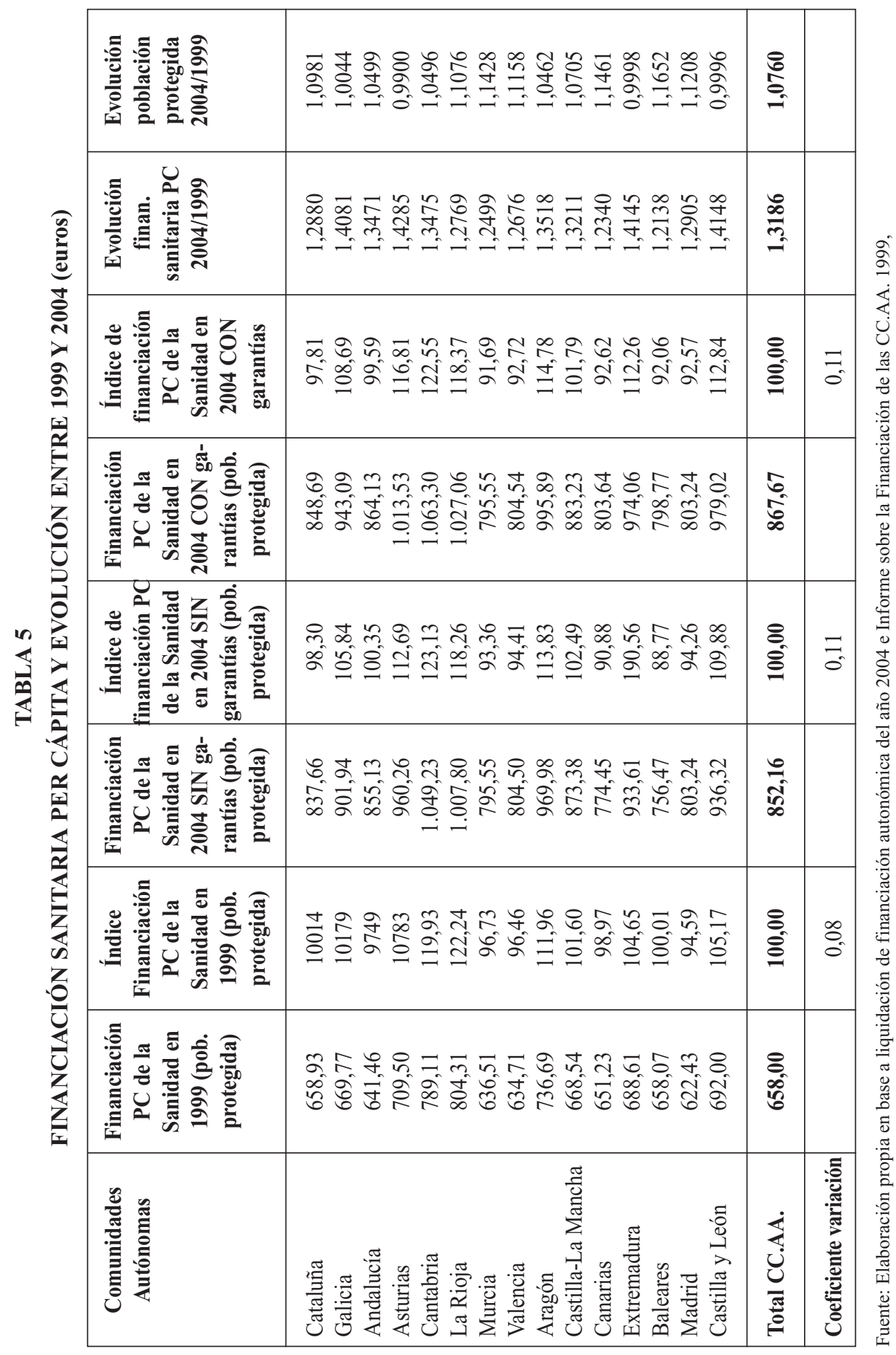


Lo importante en todo caso, tal y como se ha reflejado en el reciente Acuerdo de mejora de la financiación sanitaria del CPFF de Septiembre de 2005, es que no existe realmente un problema de insuficiencia financiera, sino que sería más bien de evolución del propio gasto sanitario. En este contexto, resulta prácticamente imposible fijar un nivel óptimo de gasto sanitario y su posterior reparto territorial, por lo que la infra/sobrefinanciación del SNS no tiene una justificación normativa clara (McGuire ySerra, 2005).

Finalmente, otras de las fuentes de desigualdades territoriales alude a la posible existencia de un «déficit sanitario» que puede entenderse como la diferencia entre el volumen de recursos disponibles para la prestación de servicios sanitarios y el gasto efectivamente realizado. La estimación de dicho déficit es un ejercicio complejo, tanto desde la perspectiva del gasto como desde la de los ingresos, y puede incluso no tener sentido en una descentralización fiscal «de segunda generación» (López I Casasnovas, 2005). La razón es que el modelo de financiación autonómica vigente ha hecho que la sanidad dejara de financiarse de forma específica, de ahí que el volumen de ingresos para esta partida sea el resultado de la voluntad y autonomía en el gasto de cada CCAA. Por ello, el análisis del déficit en sanidad únicamente puede ser evaluado por el lado del gasto efectivamente realizado y las tensiones registradas en los últimos años, y muy especialmente, desde 1999, año base de aplicación de las variables de reparto de la restricción inicial destinado a satisfacer las necesidades de gasto sanitario de cada CCAA (bloque de sanidad).

Otra de las dificultades al intentar estimar el déficit en sanidad es la escasa información sanitaria disponible en nuestro país (Borraz y Pou, 2005). El Grupo de Trabajo de Análisis del Gasto Sanitario Público dirigido por la IGAE al elaborar su informe en 2005 pudo constatar la fragmentación de la información del sistema de salud en las diferentes CCAA y las distintas fórmulas de gestión adoptadas por algunas de ellas lo que planteaba grandes dificultades en el acceso efectivo a dicha información, además de su comparabilidad para poder extraer conclusiones válidas a nivel general.

Con estos condicionantes previos, las dudas parecen obvias al intentar estimar un posible déficit en la sanidad. En cambio, muestra que los recursos no llegan a cubrir las necesidades reales, debido a la existencia de un volumen importante de deuda, en parte por el gasto farmacéutico, estimada en unos 6.036 millones de euros pendientes de contabilizar a finales de 2003. De esta deuda, destacan especialmente los importes registrados en Cataluña (2.175 millones de euros), Andalucía (1.558 millones de euros) y la Comunidad Valenciana (1.111 millones de euros).

\section{Desigualdades territoriales en utilización, acceso e indicadores de salud}

Además de los factores anteriormente mencionados que explicarían en parte las diferencias territoriales en gasto y financiación existen otros elementos que pueden explicarlas. 


\subsection{Desigualdades en utilización, acceso y necesidades no cubiertas (oferta)}

Existen también diferencias en la utilización de los servicios sanitarios entre ámbitos geográficos distintos, incluso en el caso en el que las poblaciones que se comparan tengan patrones de morbi-mortalidad similares. En cuanto a la justificación de estas diferencias parecen responder a factores que tienen que ver en parte con la oferta disponible (González, Urbanos y Ortega, 2004; Martín, 2006), especialmente las que se puede medir en términos de infraestructura física más que otras (cobertura de programas asistenciales y carteras de servicios) (Tabla 6). Aparecen así diferencias significativas («desigualdades visibles») en Atención Primaria (y la implantación del nuevo modelo) y Especializada, oferta privada no benéfica, Dotaciones de aparatos de Alta Tecnología Médica-ATM (tales como aceleradores de partículas, salas de hemodinámica, gammacámaras, equipos de tomografía axial, etc. concentrados básicamente en Madrid, Cataluña, C.Valenciana y Andalucía) y oferta geriátrica y de psiquiatría. La demanda inducida por la oferta operaría también a este nivel y los trabajos empíricos demuestran que cuanto mayor es la cantidad de recursos disponibles, en términos de camas hospitalarias, alta tecnología o recursos humanos (profesionales sanitarios), mayores son los niveles de utilización («desigualdades menos visibles») (González y Barber, 2006).

No obstante, los criterios de dotación de la oferta sanitaria en nuestro país han venido respondiendo al mantenimiento del statu quo (situación de partida) o a criterios puramente políticos. Además, una mayor utilización de los servicios sanitarios no implica necesariamente mejores resultados en salud.

Así, las diferencias territoriales antes planteadas en cuanto a gasto y financiación no responden exactamente a diferencias en la oferta sanitaria. Además de afectar especialmente a los grupos sociales más vulnerables, pueden deberse bien a una sobreutilización de servicios no efectivos, que incrementan el gasto sanitario y lo convierten en innecesario, bien a una infrautilización de recursos o tecnologías de demostrada eficacia o a su mala utilización. Incluso la existencia de deseconomías de escala en CCAA con tamaños poblacionales no muy elevados (la población protegida en 2005 de La Rioja o de Cantabria es 25,64 y 13,66 veces menor respectivamente que la de Andalucía) explicaría un elevado gasto sanitario y un acentuado «hospitalocentrismo» así como el hecho de que tanto las personas mayores de 65 años como el resto de la población hagan cada vez más un mayor uso de los servicios sanitarios, no está siempre relacionado con un empeoramiento de su estado de salud (Simó, 2007; Puig-Junoy, 2007). Como pudo comprobarse anteriormente, el impacto potencial de una mayor población protegida en el SNS hace que las diferencias interregionales presionen sobre el gasto y la capacidad de acceso al servicio sanitario.

Por tanto, las desigualdades en la oferta y acceso a los servicios sanitarios (variabilidad de utilización entre áreas de salud), injustificadas en ocasiones, resultan más intuitivas que las desigualdades de salud, incluso a pesar del escaso sistema de información y, en todo caso, a que sea homogénea entre CCAA. 
TABLA 6

OFERTA SANITARIA, ACCESO Y UTILIZACIÓN

\begin{tabular}{|c|c|c|c|c|c|}
\hline Concepto & $\begin{array}{c}\text { Hospitales por } \\
100.000 \\
\text { habitantes } \\
(2004)\end{array}$ & \begin{tabular}{|c|} 
Camas públicas \\
por 1.000 \\
habitantes \\
(2004)
\end{tabular} & $\begin{array}{c}\text { Médicos por } \\
\text { hospitales por } \\
1.000 \text { habitantes } \\
(2004)\end{array}$ & $\begin{array}{c}\text { Tasa de plazas } \\
\text { ofertadas MIR } \\
\text { por millón de } \\
\text { habitantes } \\
\text { (2005 y 2002) }\end{array}$ & $\begin{array}{c}\text { Altas } \\
\text { hospitalarias } \\
\text { por } 100.000 \\
\text { habitantes } \\
\text { (2005) }\end{array}$ \\
\hline Andalucía & 1,18 & 2,22 & 1,22 & 122,17 & 9.410 \\
\hline Aragón & 2,21 & 3,52 & 1,88 & 102,67 & 11.965 \\
\hline Asturias & 1,89 & 3,00 & 1,61 & 81,94 & 11.936 \\
\hline Baleares & 2,44 & 2,84 & 1,44 & 42,53 & 13.844 \\
\hline Canarias & 2,34 & 2,92 & 1,43 & 67,80 & 9.465 \\
\hline Cantabria & 1,84 & 2,53 & 1,53 & 193,84 & 10.700 \\
\hline Castilla y León & 1,83 & 3,03 & 1,32 & 80,23 & 11.436 \\
\hline Castilla-La Mancha & 1,49 & 2,18 & 1,41 & 31,42 & 9.197 \\
\hline Cataluña & 2,77 & 2,55 & 1,63 & 86,07 & 12.055 \\
\hline C. Valenciana & 1,34 & 2,19 & 1,31 & 75,35 & 10.634 \\
\hline Extremadura & 1,88 & 3,51 & 1,36 & 51,26 & 10.224 \\
\hline Galicia & 1,74 & 3,00 & 1,39 & 69,41 & 10.875 \\
\hline Madrid & 1,21 & 2,13 & 1,35 & 183,09 & 10.627 \\
\hline Murcia & 2,00 & 2,22 & 1,32 & 66,83 & 10.899 \\
\hline Navarra & 2,29 & 3,00 & 2,51 & 193,77 & 12.526 \\
\hline País Vasco & 2,10 & 2,47 & 1,25 & 67,83 & 11.371 \\
\hline La Rioja & 1,75 & 3,04 & 1,38 & 53,26 & 9.769 \\
\hline Ceuta & 2,89 & 3,03 & 1,55 & n.d. & 9.761 \\
\hline Melilla & 2,89 & 3,03 & 1,55 & n.d. & 9.646 \\
\hline Promedio & 1,86 & 2,64 & 1,40 & 135,84 & 10.780 \\
\hline $\begin{array}{l}\text { Coeficiente } \\
\text { Variación (\%) }\end{array}$ & 0,27 & 0,16 & 0,20 & 0,41 & 0,11 \\
\hline
\end{tabular}

Fuente: Elaborado a partir de Estadística de Indicadores Hospitalarios (2004), Encuesta de Morbilidad Hospitalaria (2005). n.d: no disponible.

Es cierto que tras las transferencias sanitarias de 2002, se ha producido una ampliación de las carteras de los SRS, así como mejoras interregionales del acceso, pero siguen existiendo desigualdades en los tiempos de acceso en términos de listas de espera. Dichas listas no han de entenderse siempre como indicadores de ineficiencia. En ocasiones pueden ser convenientes para una gestión óptima de recursos escasos, si bien en nuestro país su desconocimiento sólo se ha abordado desde una perspectiva global a partir de la Ley de Cohesión y Calidad del SNS de 2003 y el RD 605/2003, de 23 de mayo, por el que se establecen las medidas para el tratamiento homogéneo 
de su información. No obstante, más de la mitad de los españoles $(51,2 \%)$ considera que la situación de las listas de espera no ha cambiado en los últimos años, tanto para consultas como para hospitalización, y más del $35 \%$ asegura tener que esperar más de 3 meses para consultar con un especialista, según se desprende del Barómetro Sanitario del año 2006

\subsection{Desigualdades en salud}

La inequidad puede entenderse también en términos de desigualdades («injustas») en salud (input o componente del capital humano que genera bienestar), siendo éstas objeto de planes específicos en algunas CCAA y más importantes que las diferencias en utilización de servicios sanitarios. En la Tabla 7 se muestra como las desigualdades en salud entre CCAA medidas a través de las diferencias entre algunos indicadores seleccionados se mantienen entre ellas e incluso aumentan si las comparasemos en el tiempo en términos de esperanza de vida (al nacer, libre de incapacidad, en buena salud), tasa de mortalidad infantil y autovaloración de salud. Asimismo, los indicadores de salud muestran un patrón de desigualdad Noroeste-Suroeste (Benach et al., 2001).

Por otro lado, puede que en ocasiones incluso gastando más no se consigan mejores resultados en salud y patrones de morbimortalidad. Ejemplos como el de los Estados Unidos, que dedican más recursos a sanidad que España sin conseguir indicadores de salud similares, deben hacernos reflexionar acerca de la efectividad de la política sanitaria, tal y como se ha orientado tradicionalmente.

A modo de ejemplo, según López I Casasnovas et al. (2005), hacia el año 2000 los resultados de salud no eran mejores en las CC AA con transferencias sanitarias que en las del Insalud Gestión Directa. La mortalidad evitable mostraba así una pauta Norte-Sur que estaría en correlación con el gasto sanitario per capita, sin correlaciones significativas entre desigualdades regionales en el gasto sanitario y desigualdades en los indicadores de salud. Si las diferencias geográficas en salud se deben a las actuaciones - $\mathrm{o}$ a la falta de actuaciones - del sistema sanitario, $\mathrm{o}$ se deben a otros factores, como los estilos de vida donde en las últimas Encuestas Nacionales de Salud (2001, 2003 y 2006) y en el Panel de Hogares de la Unión Europea (2000) evolucionan negativamene, es una cuestión abierta pués cierto tipo de desigualdades en salud (y, por ende, relacionadas con desigualdades sociales) pueden corregirse con políticas sanitarias específicas. El Gráfico 1 muestra como un problema real de salud como es la obesidad es mayor en las CC AA de menor renta y, por ende, con menor gasto sanitario en muchas ocasiones (Cantarero y Pascual, 2006).

La mayoría de estudios de sección cruzada muestran que al aumentar el nivel de renta está se traduce en mayor gasto sanitario en relación al PIB. Así, el coeficiente estimado de la renta per capita es igual o mayor que la unidad, lo que calificaría a la sanidad como «bien de lujo» más que necesario. No obstante, no existe consenso en 
TABLA 7

INDICADORES DE SALUD

\begin{tabular}{|l|c|c|c|c|c|}
\hline \multicolumn{1}{|c|}{ Concepto } & $\begin{array}{c}\text { Esperanza de } \\
\text { vida al nacer } \\
\text { (2002). años }\end{array}$ & $\begin{array}{c}\text { Esperanza de } \\
\text { vida Libre de } \\
\text { Incapacidad } \\
\mathbf{( 2 0 0 0 )}\end{array}$ & $\begin{array}{c}\text { Esperanza de } \\
\text { Vida en Buena } \\
\text { Salud (2002) }\end{array}$ & $\begin{array}{c}\text { Tasa de } \\
\text { mortalidad } \\
\text { infantil (2002) }\end{array}$ & $\begin{array}{c}\text { Autovaloración } \\
\text { de salud - } \\
\text { Buena (2003) } \\
\text { en \% }\end{array}$ \\
\hline Andalucía & 78,44 & 67,90 & 51,20 & 4,90 & 54,30 \\
Aragón & 80,23 & 72,80 & 60,30 & 4,90 & 67,80 \\
Asturias & 79,50 & 71,10 & 50,90 & 4,30 & 54,20 \\
Baleares & 79,40 & 71,30 & 51,40 & 3,90 & 49,00 \\
Canarias & 78,58 & 70,40 & 47,50 & 4,20 & 49,40 \\
Cantabria & 80,21 & 71,10 & 54,70 & 3,50 & 55,30 \\
Castilla y León & 80,18 & 71,00 & 51,30 & 3,30 & 51,70 \\
Castilla La Mancha & 80,94 & 70,70 & 59,50 & 4,90 & 64,00 \\
Cataluña & 79,89 & 70,70 & 56,00 & 3,40 & 53,50 \\
C. Valenciana & 78,89 & 70,90 & 59,30 & 3,80 & 65,90 \\
Extremadura & 79,25 & 70,00 & 52,90 & 3,30 & 54,30 \\
Galicia & 79,88 & 70,60 & 48,60 & 4,10 & 49,40 \\
Madrid & 80,63 & 73,10 & 57,70 & 3,60 & 59,40 \\
Murcia & 78,93 & 67,70 & 54,00 & 6,20 & 56,30 \\
Navarra & 80,87 & 72,80 & 60,20 & 2,60 & 58,30 \\
País Vasco & 80,13 & 72,80 & 59,50 & 3,40 & 59,80 \\
La Rioja & 80,52 & 75,10 & 62,30 & 5,40 & 66,70 \\
Ceuta & 78,20 & 68,00 & 51,20 & 10,80 & 55,20 \\
Melilla & 78,00 & 68,00 & 51,20 & 9,50 & 55,20 \\
\hline Promedio & 79,70 & 70,70 & 55,10 & 4,10 & 56,80 \\
\hline Coeficiente & 0,01 & 0,02 & 0,08 & 0,51 & 0,10 \\
Variación (\%) & & & & & \\
\hline & & & & & \\
\hline
\end{tabular}

Fuente: Elaborado a partir de Ministerio de Sanidad y Consumo (2006).

la literatura acerca de si realmente es un bien de lujo o normal dependiendo del ámbito de estudio considerado: por países o en cada uno de ellos (Di Matteo, 2003; Sen, 2005).

En este sentido, más gasto en sanidad especialmente en los países desarrollados como España y, en su caso a nivel territorial, puede no suponer mejoras claras en los indicadores básicos de salud (esperanza de vida, reducción de tasas de mortalidad infantil, etc). Ello se debería a que estos países estarían alcanzando la parte en la que se producen rendimientos decrecientes en la produción sanitaria, lo que junto con el aumento de los costes marginales del gasto sanitario apenas mejoraría los resultados en salud (Appleby y Harrison, 2006; Martín, 2006; Pita Barros, 2006). La literatura 


\section{GRÁFICO 1}

\section{CC.AA. CON ÍNDICES DE MASA CORPORAL (IMC) POR ENCIMA DE MEDIA NACIONAL}
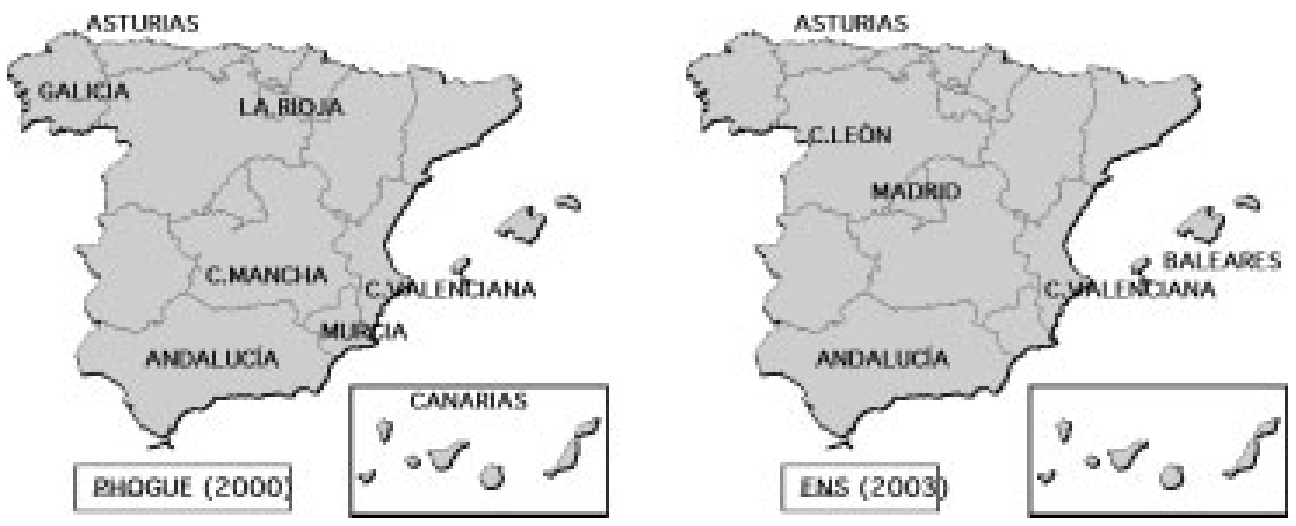

Nota: IMC medio en ENS (2003) es 27,56 y en PHOGUE (2000) es 25,10

Fuente: Elaboración propia a partir de la ENS (2003) y PHOGUE 2000 (muestra ampliada).

no es concluyente al respecto y muestra en ocasiones como la descentralización territorial de la Sanidad no conduce a mejoras de salud (Peckham et al., 2005) al no mejorar la eficiencia de las organizaciones, si bien en Nixon y Ullmann (2006) o Cantarero y Pascual (2007) se muestra como en un contexto más descentralizado pueden seguir mejorandose los indicadores de salud.

Asimismo, las expectativas y actitudes sociales de los ciudadanos indican según el Barómetro Sanitario que la satisfacción con el sistema entre los ciudadanos es de un $69,7 \%$ (dos puntos más que un año antes), si bien difiere entre CC AA (Centro de Investigaciones Sociológicas, 2007). Lo mismo ocurre con la percepción de la calidad de los servicios sanitarios públicos de la CCAA por comparación con las demás o con la percepción de discriminación por calidad asistencial.

En cuanto a la influencia de la CCAA de residencia, el 46,6\% cree que se pres$\tan$ los mismos servicios en todas las CCAA; el 30,2\% opina lo contrario y el 22,9\% no tiene opinión. En cuanto a la gestión de los servicios por parte de las CCAA o del Estado, la cuarta parte de los encuestados no tiene una opinión formada al respecto, mientras que el 36,3\% cree que se recibe el mismo servicio en cualquiera de los casos. Por otra parte, una gran mayoría (84\%) se decanta por la necesidad de que las CCAA se coordinen la hora de ofertar nuevos servicios.

\section{Conclusiones}

En este trabajo se ha estudiado para el caso sanitario la relación existente entre sus diferencias autonómicas en gasto y financiación, diversas variables relacionadas con la oferta de servicios sanitarios (acceso y utilización) e indicadores de salud, se plan- 
teaba la cuestión de si las desigualdades que se observaban están justificadas, por ejemplo, por diferencias en la población cubierta, por la necesidad de aprovechar las economías de escala (motivos de eficiencia, entendida como relación entre recursos invertidos y resultados alcanzados), etc., o se trataba más bien de diferencias poco justificables.

A este respecto, en los últimos años se ha producido un desfase entre la evolución de los recursos autonómicos y la dinámica del gasto en sanidad. Los recursos procedentes de los diferentes acuerdos de financiación se han mostrado hasta la fecha insuficientes para poder atender las crecientes necesidades de gasto sanitario y sería necesario repensar la racionalidad de los criterios actuales de financiación sanitaria.

Tras la finalización del traspaso de la sanidad a las CCAA, éstas han pasado a gestionar gran parte del conjunto de gasto sanitario observándose como las partidas de mayor peso son las de personal, seguidas de las de transferencias corrientes (básicamente, gasto en recetas médicas) y la compra de bienes y servicios. Esto hace que el margen de maniobra presupuestario de las CCAA en sus presupuestos sanitarios sea escaso si quieren emprender políticas de contención del gasto. Parece entonces lógico que, junto a la necesidad de incrementar los recursos financieros destinados a sanidad, se introduzcan medidas de racionalización del gasto sanitario autonómico, si además tenemos en cuenta que la descentralización ha supuesto en muchos casos la duplicación de servicios en CCAA al existir pocos incentivos a participar en acuerdos de cooperación entre las CCAA.

Dado que las CCAA siguen precisando de recursos financieros para la sanidad, éstos no deberían proceder únicamente del ejercicio de su capacidad normativa en los tributos de su competencia, ya que tendría sentido para mejorar el nivel de prestación pero no para mantener una situación de partida que podría ser deficitaria. Así, se debería incorporar al cálculo de las necesidades de gasto algo que no está contemplado en el modelo actual y que es una cartera de servicios común para definir así un nivel estándar de prestación sanitaria.

En el trabajo se ha descrito el funcionamiento del sistema actual de financiación territorial autonómica analizandose sus últimas liquidaciones. Lo importante en todo caso, y tal y como se ha reflejado en el reciente Acuerdo de mejora de la financiación sanitaria de 2005, es que el problema es de evolución del propio gasto sanitario (necesidades), en parte motivado por un fuerte desequilibrio vertical que genera insuficiencia de recursos para el conjunto de CCAA.

Se observa también la ausencia de patrón redistributivo dada la dispersión en el año base (situación de partida) de aplicación del modelo de financiación sanitaria autonómica tanto per capita como con índice ponderado y la evolución del modelo mantiene esa dispersión. Así, las diferencias en la ordenación de CC.AA según su situación de partida, incremento en cantidad y calidad de las prestaciones, coste de los factores productivos, niveles de acceso y utilización (oferta sanitaria relacionada con la renta y grado de descentralización), indicadores de salud (patrones de morbimortalidad), expectativas y actitudes de los ciudadanos no concuerdan con la ordenación según criterios de gasto (o financiación) en sanidad y ni incluso fórmulas sofisticadas de asigna- 
ción descentraliada de recursos según necesidades han podido explicarlas. En consecuencia, las diferencias en los niveles de gasto público (y su financiación con falta de corresponsabilidad fiscal de las CCAA) en Sanidad (por ejemplo, per capita) no deben ser empleadas como indicadores de equidad territorial, siendo ésta última un concepto más normativo que contrastable a la luz de la evidencia empírica.

\section{Referencias bibliográficas}

[1] ARTELLS, J. (2005): Desarrollo y sostenibilidad del Sistema Nacional de Salud descentralizado. Fundación Salud, Innovación, Sociedad.

[2] APPLEBY J. y HARRISON, A. (2006): Spending on Health Care. How much is enough? King's Fund.

[3] BANTING, K.G. y CORBETT, S. (2002): Health Policy and Federalism. A Comparative perspective on multi-level governance. Kingston: McGill-Queen's University Press.

[4] BENACH, J., YASUI, Y., BORRELL, C., ROSA, E., PASARIN, I., BENACH, N., ESPAÑOL, E. MARTINEZ, J.M. y DAPONTE, A. (2001): Atlas de mortalidad en areas pequeñas en España (1987-1995). Barcelona: Universidad Pompe Fabra.

[5] BORRAZ, S. y POU, V. (2005): «Razones para una reforma de la financiación del gasto sanitario». Cuadernos de Información Económica; 188: 51-61.

[6] CABASES, J. C. (ed.) (2006): La financiación del gasto sanitario desde la perspectiva de la experiencia comparada. Madrid: Fundación BBVA.

[7] CANTARERO, D. (2003): «Análisis del gasto sanitario autonómico y su nueva financiación en España». Madrid: Investigaciones; n. ${ }^{\circ}$ 8/03, Instituto de Estudios Fiscales.

[8] CANTARERO, D. (2005): «Decentralization and health care expenditure: The Spanish case». Applied Economics Letters; 12 (15): 963-966.

[9] CANTARERO, D. y FERNANDEZ GOMEZ, N. (2007): «La reforma de la financiación autonómica: necesidades y alternativas». Revista de Estudios Regionales, en prensa.

[10] CANTARERO, D. y PASCUAL, M. (2006): «El problema de la obesidad: el caso de las regiones españolas». Estudios de Economía Aplicada, 24-3, Diciembre, 837-859.

[11] CANTARERO, D. y PASCUAL, M. (2007): «Analyzing the impact of fiscal decentralization on health outcomes: empirical evidence from Spain». Applied Economics Letters, 15(2): 109-111.

[12] CENTRO DE INVESTIGACIONES SOCIOLÓGICAS (CIS) (2007): Barómetro sanitario 2006.

[13] COSTA-FONT, J. y PONS-NOVELL, J. (2006): «Public health expenditure and spatial interactions in a decentralized national health system». Health Economics; 16(3): 291-306.

[14] DE LA FUENTE. A. y GUNDIN, M. (2007): «El sistema de financiación de las Comunidades Autónomas de régimen común: situación actual, perspectivas y propuestas de reforma». Workshop sobre la Financiación en los Nuevos Estatutos Autonómicos, IAE, 8 de Febrero de 2007, Barcelona. 
[15] DI MATTEO, L. (2003): «The income elasticity of health care spending A comparison of parametric and nonparametric approaches». European Journal of Health Economics; 4: 20-29.

[16] GARCIA GOÑI, M. (2006): «Análisis descriptivo del gasto sanitario español: evolución, desglose, comparativa internacional y relación con la renta». Papeles de Trabajo del Instituto de Estudios Fiscales; PT N. . . 24/06.

[17] GARCIA GOMEZ, P.y LOPEZ NICOLAS, A. (2004): «Regional differences in socio-economic health inequalities in Spain». Working Paper $n .{ }^{\circ} 40$, Research Centre on Health Economics (CRES), Universidad Pompeu Fabra.

[18] GIANNONI, M. y HITIRIS, T. (2002): The regional impact of health care expenditure: the case of Italy. Applied Economics; 14: 1829-1836.

[19] GONZALEZ, B., BARBER, P. (2006): «Desigualdades territoriales en el Sistema Nacional de Salud (SNS) de España». Documentos de Trabajo de la Fundación Alternativas 90/2006.

[20] GONZALEZ, B., URBANOS, R.M. y ORTEGA, P. (2004): «Oferta pública y privada de servicios sanitarios por Comunidades Autónomas». Gaceta Sanitaria; 18(supl. 1): 82-89.

[21] GORDO J.L. (2002): «El sistema retributivo del SNS y su perspectiva de futuro». Revista de Administración Sanitaria; VI(23): 39-66.

[22] INSTITUTO NACIONAL DE ESTADISTICA (INE) (varios años): Estadística de Indicadores hospitalarios. Madrid: INE.

[23] INSTITUTO NACIONAL DE ESTADISTICA (INE) (varios años): Encuesta de Morbilidad Hospitalaria. Madrid: INE.

[24] INTERVENCION GENERAL DE LA ADMINISTRACION DEL ESTADO (IGAE): Informe del Grupo de Trabajo del Análisis del Gasto Sanitario. Madrid: MSC.

[25] LOPEZ I CASASNOVAS, G. (2004): «La gestión sanitaria: orientaciones a futuro para el cambio organizativo, de control y la financiación». Cuadernos Económicos del ICE; 67: 49-62.

[26] LOPEZ I CASASNOVAS, G. (2005): «Descentralización sanitaria de segunda generación». XXV Jornadas de la Asociación de Economía de la Salud (AES). Barcelona: 59-70.

[27] LOPEZ I CASASNOVAS, G., COSTA-FONT, J., y PLANAS, I. (2005): «Diversity and regional inequalities in the Spanish 'system of health care services'». Health Economics; 14(1): S221-S235.

[28] MARTIN, J.J. (2006): «Balance crítico de la descentralización territorial de la sanidad'». Un balance del Estado de las Autonomías; Colección estudios socioeconómicos, Fundación Cajamar: 385-404.

[29] MCGUIRE, G. y SERRA, V. (2005): «The cost of care. Is there an optimal level of expenditure?'». Harvard Internacional Review; 27(1).

[30] MINISTERIO DE ECONOMÍA Y HACIENDA (varios años): Financiación de las CCAA por los impuestos cedidos, Fondo de Suficiencia y Garantías de financiación de los servicios de asistencia sanitaria en el año 2002, 2003 y 2004 y liquidación definitiva de dicho ejercicio, Julio 2004, 2005 y 2006.

[31] MINISTERIO DE SANIDAD Y CONSUMO (2006): Principales cifras del SNS.

[32] NIXON, J. y ULLMANN, P. (2006): «The relationship between health care expenditure and health outcomes'». Europea Journal of Health Economics; 7: 7-18. 
[33] OECD (2006a): «Projecting OECD health and long-term care expenditures: what are the main drivers?». Economics Department, Working Paper OECD, n. ${ }^{\circ} 477$.

[34] OECD (2006b): OECD Health Data File 2006. Paris.

[35] PECKHAM, S., EXWORTHY, M., POWELL, M., y GREENER, I. (2005): Decentralisation as an organisational model for health care in England. Report to the NHS NCC-SDO research and development programme.

[36] PITA BARROS, P. (2006): «Gasto sanitario: ¿es más siempre mejor?». Revista Asturiana de Economía; 7 -

[37] PUIG-JUNOY, J. (2007): «Tensiones actuales y futuras sobre el bienestar sanitario. A la búsqueda del necesario equilibrio entre lo deseable y lo sostenible». Papers de la Fundació Rafael Campalans; 148.

[38] REY, J. (1998): Descentralización de los servicios sanitarios. Consideraciones generales y análisis del caso español. Granada: Escuela Andaluza de Salud Pública.

[39] RUIZ-HUERTA, J. y GRANADO, O. (2003): «La sanidad en el nuevo modelo de financiación autonómica». Documentos de Trabajo 31/2003, Fundación Alternativas.

[40] SEN, A. (2005): «Is health care a luxury? New evidence from OECD Data». International Journal of Health Care Finance and Economics; 5: 147-164.

[41] SIMO, J. (2007): «El gasto sanitario en España, 1995-2002. La atención primaria, Cenicienta del Sistema Nacional de Salud». Atención Primaria; 39(3): 127-132.

[42] URBANOS, R. (2001): «La financiación sanitaria en los países de nuestro entorno». Revista de Administración Sanitaria; V(18): 95-106.

[43] URBANOS, R. (2006a): »El acuerdo de financiación sanitaria y su repercusión para el Sistema Nacional de Salud». Presupuesto y Gasto Público; 42: 229-240.

[44] URBANOS, R. (2006b): »El gasto sanitario y su financiación: evolución, tendencias y reflexiones para el futuro». Revista Asturiana de Economía; 35: 45-65. 